Fig. 2. Per cent of total contact time on each surrogate surface, for each of the pairs presented.

Table 2

Comparisons of Mean Contact Time in Min for Each Pair of Surrogate Surfaces Presented

\begin{tabular}{|c|c|c|c|}
\hline Pair & $\begin{array}{c}\text { Mean } \\
\text { Difference } \\
\end{array}$ & $\begin{array}{l}t \text { (1-tail, } \\
5 \mathrm{df})\end{array}$ & $\mathbf{p}$ \\
\hline Cloth-rayon & 8.22 & 2.22 & $<0.05$ \\
\hline Cloth-vinyl & 7.50 & 2.09 & $<0.05$ \\
\hline Cloth-sandpape & er 16.90 & 26.82 & $<0.0005$ \\
\hline Rayon-vinyl & 2.65 & 1.07 & n.s. \\
\hline Rayon-sandpap & per 4.78 & 3.73 & $<0.01$ \\
\hline Vinyl-sandpape & er 2.66 & 3.37 & $<0.01$ \\
\hline
\end{tabular}

investigators. It is perhaps fortunate that the preferred surface was the cotton sock, since an investigator must serve two masters, his animals and his budget, and cotton socks are by far cheaper to purchase and launder than are the other types of surfaces tested.

On the whole, infants spent little time contacting sandpaper-covered surrogates, and what contact did exist was incidental or exploratory in nature. While they spent some time sitting or sleeping on all the other surfaces, they never displayed either of these behaviors on the sandpaper, and no sensible primate would. In view of the trend towards greater total contact time on the cloth surface when it was paired with the sandpaper surface, the hypothesis is advanced that since the aversive substance produced greater avoidance, it may have acquired characteristics similar to those of a fear stimulus. The substance giving greatest contact comfort also probably imparted more security to the infant (as was found by Harlow, 1958), and the infant therefore spent a greater total amount of time on this surface. This difference is also reflected in the minimum duration of contact time with cloth in the presence of the other three substances. When paired with rayon, the minimum contact time was $0 \mathrm{~min}$, with vinyl, $4.88 \mathrm{~min}$, and with sandpaper, $15.18 \mathrm{~min}$.

This experiment also demonstrated the value of the "mini-experiment" in work other than operant research. This is a type of experiment in which few Ss are used, even though the experiment is in itself complete and need not be regarded merely as a pilot study.

\section{REFERENCES}

HARLOW, H. F. The nature of love. American Psychologist, 1958, 13, 673-685.

HARLOW, H. F., \& SUOMI, S. J. The nature of love-simplified. American Psychologist, in press.

STEEL, R. G. D., \& TORRIE, J. H. Principles and procedures of statistics. New York: McGraw-Hill, 1960.

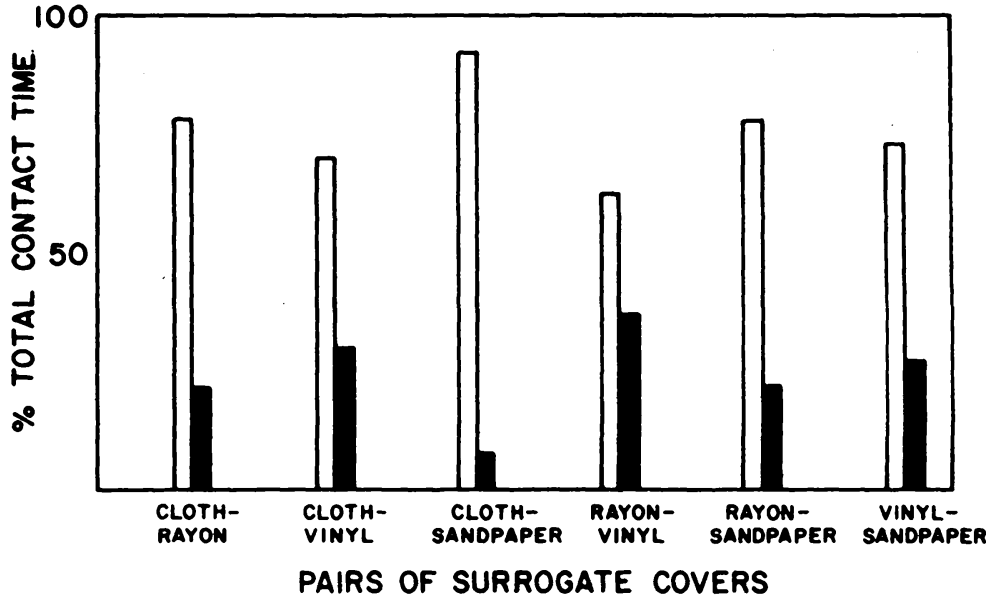

Table 3

Mean Total Contact Time 30 Min Periods for Each of the Pairs of Surrogate Surfaces and Differences Between Means as Compared by the New Duncan Multiple Range Test

\begin{tabular}{lrlr}
\hline \multicolumn{1}{c}{ Pair } & Mean & Significant Differences & $p$ \\
\hline Cloth + sandpaper & 20.02 & Cloth + sandpaper - vinyl + sandpaper & $<0.01$ \\
Cloth + vinyl & 18.57 & Cloth + sandpaper - rayon + sandpaper & $<0.05$ \\
Cloth + rayon & 14.41 & Cloth + vinyl - vinyl + sandpaper & $<0.05$ \\
Rayon + vinyl & 12.79 & Cloth + vinyl - rayon + sandpaper & $<0.05$ \\
Rayon + sandpaper & 8.59 & & \\
Vinyl + sandpaper & 5.76 & & \\
\hline
\end{tabular}

\section{NOTE}

1. This research was supported by United States Public Health Service Grants MH-11894 and FR-0167 from the National Institutes of
Health to the University of Wisconsin Primate Laboratory and Regional Primate Research Center, respectively. The authors also wish to thank Mrs. Sue Appert for her assistance in testing the animals.

\title{
Heart rate as a function of water deprivation and conditioning: Some additional controls ${ }^{1}$
}

ROBERT GOLDSTEIN, JOHN A. STERN, and LORI STURMFELS, Washington University, St. Louis, Mo. 63104

Heart rate (HR) was recorded from 23.5 . and 47.5-h water-deprived rats during 12 days of adjustment to the deprivation schedules and throughout subsequent conditioning. No HR effects of deprivation perse were noted, but a significant - tachycardia developed during conditioning. $A$ 47.5-h deprived group never given water in the apparatus throughout the entire deprivation period lapproximately 60 days) failed to manifest this response. Thus, several potential sources of artifact in a prior study were eliminated.

In a previous report (Goldstein, Stern, \& Rothenberg, 1966), evidence consistent with Malmo's (1959) activation hypothesis was presented in which the heart rate (HR) of water-deprived rats was observed to increase in the presence of stimuli associated with water. In that study, however, several potential sources of artifact existed; the present study was 
designed to elucidate or to control them.

First, in the prior study, the initiation of conditioning trials following adaptation coincided with the onset of the deprivation schedules. The relative tachycardia that developed progressively in the deprived animals might have been a function of adaptation to the deprivation regimen rather than to conditioning. Second, where the ad lib and 23.5-h-deprived Ss were run every day, the 47.5-h-deprived rats were run on alternate days; it is conceivable that the more distributed schedule of the $47.5-\mathrm{h}$ group could contribute to the higher HR.

In addition to controlling for these variables, it was decided to introduce another group of 47.5-h animals who were never given water in the test chamber. In so doing, factors other than access to water in that situation that might give rise to an accelerative HR could be ruled out.

\section{SUBJECTS AND APPARATUS}

Twenty-nine male albino rats, 99 days old at the initiation of the study, served as Ss.

The test apparatus consisted of a six-compartment plywood box identical to that used previously (Goldstein et al, 1966). It was located in an $8 \times 8 \mathrm{ft}$ sound-attenuated and electrically shielded room illuminated by a single $150-\mathrm{W}$ bulb centered above the apparatus and approximately $5 \mathrm{ft}$ above the floor of the box. A one-way vision glass allowed observation of the animals from the location of the polygraph outside the room.

\section{PROCEDURE}

Eight days after receipt of the 91-day-old Ss, they were lightly anesthetized with ether and were implanted with 18-gauge wire loops according to the procedure described by Stern \& Word (1961).

For the next 36 days, all Ss were run every day (in squads of six) in an attempt to reduce their initial HR level. Immediately following the recording session on Day 36, water deprivation was begun. The Ss were divided randomly into four groups: Group $\mathrm{Z}(\mathrm{Oh}$ deprived, $\mathrm{N}=7)$, Group $\mathrm{T}\left(23 \frac{1}{2} \mathrm{~h}\right.$ deprived, $\left.\mathrm{N}=8\right)$, Group FW (471/2 h deprived who were to receive water in the test chamber, $N=7$ ), and Group FNW (471/2 $\mathrm{h}$ deprived, no water in the test apparatus, $N=7$ ). Two days later and on alternate days throughout the study, all Ss were run for $6 \mathrm{~min}$. On the first 11 of these recording days, $E$ entered the experimental room after $4 \mathrm{~min}$ and rotated the frame on which were mounted empty water tubes, so that approximately 1 in. of the tubes extended into the box. On the 21 succeeding recording days (conditioning phase), the same procedure was followed except that the water tubes were filled for all but the Group FNW animals.

All deprived Ss were watered for $1 / 2 \mathrm{~h}$ following each run. In addition, on nonrunning days, the Group $T$ rats were watered in their home cages at the normal time.

\section{HEART-RATE MEASURES}

Heart rate samples, $10 \mathrm{sec}$ in duration, were taken immediately after introducing the Ss into the recording box and, again, 4 min later, i.e., prior to entrance of $E$ into the experimental room. Though HR was also sampled during drinking, no additional information was contributed by these data, and they will not be reported.

The means of the 0-and 4-min measures were calculated for each animal and represent the basic data of this study.

\section{RESULTS}

The HR of the various groups during the three phases of the experiment are displayed in Fig. 1. With the exception of the adaptation point that represents the last 10 consecutive adaptation days, all points are means of four recording sessions which, as indicated above, took place on alternate days.

As can be seen, there was a negligible differential change in $H R$ in the four groups in the initial deprivation period. In this phase, Group FW showed a slight overall deceleration, while Group FNW responded in a manner almost identical to the ad lib controls. It is to be noted that these groups were treated identically during this period. In terms of absolute HR during this entire phase, the three groups (FW and FNW pooled) showed identical means: $14.6 \mathrm{~b} / 2 \mathrm{sec}$.

A repeated-measures analysis was run on the conditioning data from the final deprivation point throughout conditioning. The two main effects, treatment and trials and their interaction, were significant ( $p<.05$, in each case). Comparing Group T and Group Z in a separate analysis resulted in significant trials and interaction effects $(p<.05)$ but absence of a treatment effect. In a similar analysis of Group T vs Group FW, however, only the trials effect achieved significance.

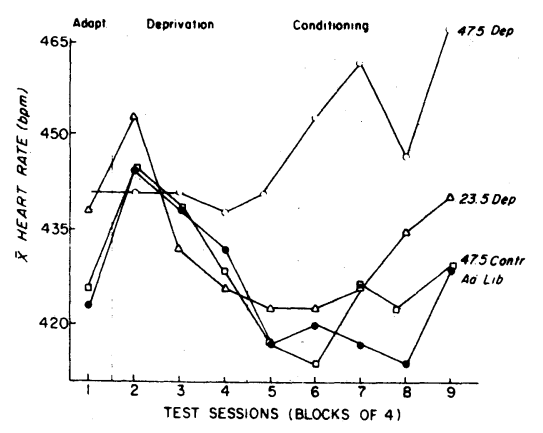

Group FNW was statistically indistinguishable from Group $Z$.

One might add that the initial adaptation sessions during which HR showed some habituation served the desired end by allowing the HR-conditioned response to develop incrementally across conditioning trials in the more conventional manner rather than the differential decrease taken as evidence of learning in Goldstein et al (1966).

\section{DISCUSSION}

These data clearly confirm the conclusions arrived at in the previous study (Goldstein et al, 1966). Thus, in a period of about 20 days, during which Ss were adapting to the various deprivation regimens, no differences in $H R$ were observed vis a vis an ad lib control group. Furthermore, a group maintained on a $47 \frac{1}{2}-\mathrm{h}$ deprivation schedule for an additional $\mathbf{4 0}$ days, approximately, showed no HR alteration, despite the fact that, in the final block of trials, these Ss were at about $70 \%$ of their estimated body weights (based on control growth), which represents a considerable deficit.

It is clear, too, from the present investigation that the distributed schedule of running was not the source of the tachycardia evidenced by the $471 / 2-h$ group in the prior research since all Ss here were run on the same (alternate day) schedule. The exposure of the Ss to stimuli associated with water represented a necessary condition for activation to occur.

It can be stated then, with added confidence, along with Malmo (1959), Malmo \& Bélanger (1967), and others since, that activation, autonomically indexed, is an interactive function of an altered internal state coupled with relevant external stimuli.

\section{REFERENCES}

GOLDSTEIN, R., STERN, J. A., \& ROTHENBERG, S. J. Effect of water deprivation and cues associated with water on the heart rate of the rat. Physiology \& Behavior, 1966, 1, 199-203.

MALMO, R. B. Activation: A neurophysiological dimension. Psychological Review, 1959, 66, 367-386.

MALMO, R. B., \& BÉLANGER, D. Related physiological and behavioral changes: What are their determinants? Research Publication of the Association for Nervous \& Mental Diseases, 1967, 45, 288-313.

STERN, J. A., \& WORD, T. J. Change in cardiac response of the albino rat as a function of electroconvulsive seizures. Journal of Comparative \& Physiological Psychology, 1961, 54, 389-394.

\section{NOTES}

1. This research was conducted at the Washington University Behavioral Research Laboratory facility at Malcolm Bliss Mental Health Center in St. Louis and was supported in part by USPHS Training Grant MH 7081. Requests for reprints should be sent to $R$. Goldstein, Malcolm Bliss Mental Health Center, 1420 Grattan St., St. Louis, Mo. 63104. 